\title{
O Mercosul após o Protocolo de Ouro Preto
}

\author{
LUIZ OLAVO BAPTISTA
}

$\mathrm{O}$ MERCOSul É CRIATURA Do Tratado de Assunção, mas insere-se em ordem jurídica territorial mais abrangente - a do direito internacional público - e em outras ordens jurídicas, de menor alcance, que o integram e completam.

O adjetivo nova é importante, pois representa uma característica intrínseca e uma condição do Mercosul: novo na concepção, novo na existência.

Além disso - colocado entre as ordens jurídicas nacionais e a internacional, intersectando-as - tem seus próprios limites, ligados aos objetivos que nos servem de ponto de partida.

É no art. $1^{\circ}$ que o Tratado de Assunção estabelece os seus objetivos e limites. Ali se descreve o que entendem os signatários deva vir a ser o mercado comum que instituíram, e o modo como pretendem alcançá-lo.

Referindo-se ao mercado comum, o Tratado não diz o que é - cuidadoso em evitar uma rigidez de desenho e em propiciar ajustes futuros de seus rumos dado o seu caráter transitório - mas sim o que implica. São três aspectos operacionais.

O primeiro, "a livre circulação de bens, serviços e fatores produtivos" (atenção para o fato de que não se diz quais são estes últimos, ao contrário do que se fez nos Tratados de Roma) e a "eliminação dos diveitos alfandegários, restrições não-tarifária à circulação no mercado, e de qualquer outra medida de efeito equivalente". As expressões que grifei já mostraram ao intérprete advertido que o foco das atenções é o comércio. Realmente, não se pode falar em barreiras alfandegárias ou não-tarifárias à livre circulação de pessoas e capitais, pois umas e outros não estão sujeitos ao regime aduaneiro.

Fala-se no parágrafo seguinte, continuação lógica do primeiro, no "estabelecimento de uma tarifa externa comum e a adoção de uma politica comercial comum em relação a terceiros Estados ou agrupamentos de Estados", frase na qual persiste a preocupação com o aspecto do comércio de bens.

O segundo aspecto é o da "coordenação de politicas macroeconômicas e 
setoriais" que visariam a "assegurar condições adequadas de concorrência entre os Estados-partes".

O terceiro aspecto é o "compromisso dos Estados-partes de harmonizar suas legislações, nas áreas pertinentes, para lograr o fortalecimento do processo de integração".

Nada mais se pode acrescentar - salvo pela via do consenso das partes - à descrição que daí emerge. Tanto porque tratando-se de um ato que afeta a soberania das partes - que assumem em face da comunidade internacional e reciprocamente algumas obrigações - quanto porque a regra de direito sobre interpretação de tratados, bem anotada por Rezek (1), é aquela que "expressa pelas próprias partes contratantes, a interpretação autêntica parece irreplicável” (...) cumpre perquirir a expressão da vontade das partes; não há lugar, nos princípios de Viena, para a busca especulativa de sua vontade recôndita" (2). O que significa a expressão Mercado Comum, no Tratado de Assunção, é a primeira questão que nos ocorre.

A doutrina, quando define a expressão Mercado Comum (3), oferece uma descrição vaga e teórica, ou se refere a algum modelo, o mais freqüente sendo o que resultou dos Tratados de Roma e hoje se converteu na União Européia. Por isso, há quem se iluda e pense que Mercado Comum é apenas o europeu, esquecendo poder a expressão ter o significado que em cada local e época lhe é atribuído, bastando para isso confrontar o art. $1^{\circ}$ do Tratado de Assunção com os artigos $2^{\circ}$ e $3^{\circ}$ do Tratado de Roma. Desde a experiência que antecedeu à unificação alemã, à época de Bismark, passando pelo Benelux e chegando ao Mercado Comum Europeu, temos significados diferentes para uma só expressão. Aliás, o próprio Mercado Comum Europeu evoluiu de concepção mais rala, que ao longo do tempo se espessou, pouco a pouco, até atingir a consistência da União Européia.

Mas, a verdade é que seguindo a norma de direito internacional em matéria de interpretação, não se permite a assimilação enganada que alguns fazem entre as propostas do Mercosul e as do antigo Mercado Comum Europeu.

Com efeito, estamos tratando de interpretar um tratado, e aí de pouco nos acodem a doutrina e os exemplos, já que a definição será a expressa no seu texto, a qual deve ser associada ao restante dos instrumentos que se sucederam ou complementam essa convenção, assim como à conduta das partes contratantes.

O desenho que o Tratado de Assunção fornece é de um mecanismo transitório, por isso mesmo, incompleto e pendente de compleição futura. Esta só se fez até certo ponto, com a assinatura do Protocolo de Ouro Preto, e ainda se fará, como ali previsto, sempre a partir de decisões políticas, como as que foram adotadas até agora. 
Entretanto, podemos dizer com certa liberdade de linguagem que o Tratado de Assunção já carregava em si o código genético do que pode vir a ser a integração definitiva ou mais avançada. A matriz desse código genético é a maneira como estão sendo e serão conduzidos o processo de integração e a constituição do mercado comum desenhado pelo Tratado de Assunção. Consiste na opção por um sistema de cooperação entre Estados, ao invés de um regime de administração comunitária da generalidade dos setores da vida econômica.

Mas, em um sistema de cooperação, que instituições caberão e que desenho têm ou poderão ter?

\section{As instituições do Mercosul}

O Tratado de Assunção criou-as no sentido que lhes dá a teoria institucional de Hauriou ou a de Santi Romano. Não são elas, porém, organismos supranacionais. Aliás, uma leitura adequada do Tratado de Assunção e a prática posterior das partes contratantes mostram o cuidado em evitar estruturas administrativa, judicial ou legislativa fechadas (nos moldes das européias) e a escolha de modelos flexíveis, cujos limites ficam meio indefinidos, para que a prática os vá perfeccionando. Ao ser firmado, em 17 de dezembro de 1994, o Protocolo de Ouro Preto crismou essa configuração, sendo a primeira das instituições do Mercosul, englobando outras que dele fazem parte.

Em razão da opção pela cooperação entre os Estados, como o molde da construção do Mercosul, era lógico que o órgão superior fosse o Conselho do Mercado Comum (CMC), nada mais, nada menos que uma comissão de ministros das relações exteriores e da economia $(4)$ - e, conseqüentemente, que o órgão administrativo ou executivo fosse o Grupo Mercado Comum (GMC), composto de funcionários desses e de outros ministérios dos Estados-partes (5).

O Conselho, nos termos do Tratado de Assunção, pode, em seu âmbito de competência, editar medidas que obrigam os Estados. Mas - embora não se o diga claramente, vê-se na prática que o sucedeu - a execução dessas medidas incumbe aos órgãos dos governos nacionais. Com efeito, o art. $9^{\circ}$ do Protocolo de Ouro Preto dispõe que autoriza: "[o] Conselho do Mercado Comum manifestar-se-á mediante Decisões, as quais serão obrigatórias para os Estados-partes", cabendo a estes, entretanto, fazer com que tais medidas sejam implementadas no âmbito das respectivas soberanias. As decisões, na forma do art. 37 do Protocolo de Ouro Preto, "serão tomadas por consenso e com a presença de todos os Estados-partes".

Finalmente, o Protocolo de Ouro Preto estabelece, no seu art. 38, que "os Estados-partes comprometem-se a adotar todas as medidas necessárias para assegurar, em seus respectivos territórios, o cumprimento das normas emanadas dos órgãos do Mercosul previstos no art. $2^{\circ}$ deste Protocolo." 
Pela mesma razão de ter optado por um mecanismo de cooperação, e ademais não havendo contato - relação funcional direta - entre os órgãos do Mercosul e o público, não ocorrerá na prática qualquer matéria a ele relacionada que possa ser objeto de litígio no plano internacional, exceto as divergências entre os Estados-partes quando se originem da iniciativa dos governos (ou originalidade do sistema - daquela de seus súditos, no interior dos Estados, provocando a ação destes), únicos titulares do diálogo e do processo de solução de disputas. Daí porque o mecanismo de solução de disputas só poderia ser o que foi adotado - diplomático, apoiado, em última instância, por um sistema clássico de arbitragem internacional.

No seio do Mercosul, e seguindo a lógica institucional deste, os mecanismos são, pois, de natureza diplomática, econômica e inseridos num sistema de cooperação. Compõem dois grandes subsistemas que atendem ao caráter dinâmico, bem como à opção pela cooperação entre os Estados. Apresentam características próprias de suas funções: servem de canal para a criação e aplicação das normas que regerão as relações no interior do Mercosul e para resolução de eventuais divergências entre os participantes.

\section{Subsistema normativo e de controle interno}

A característica fundamental do subsistema normativo e de controle (6) interno, criado pelo Tratado de Assunção, a regra da unanimidade, ou seja do consenso, conforme se percebia do Tratado de Assunção, foi confirmada pela prática e, para maior clareza, o Protocolo de Ouro Preto, no seu art. 37 já citado, o reitera expressamente. Com efeito, não havendo uma instituição legislativa supranacional, somente a regra da unanimidade permite exprimir uma vontade que coincide com a nacional, submetendo a deliberação a um mecanismo de controle legislativo interno.

Não temos então, no Mercosul, praticamente nenhuma devolução de poderes a um órgão internacional (7). Há a criação de mais uma atribuição administrativa dos Ministros originada na ordem interna, mas que se exerce concomitantemente na ordem internacional, apoiada numa ponte que é o Tratado - ancorado nas duas ordens. Age num processo deliberativo dentro das matérias de sua competência nacional e daquela que o Tratado designa. Essa atribuição é fundamentalmente a da negociação de tratados, de manutenção de negociações diplomáticas para resolver eventuais divergências e, subsidiariamente, de promoção da harmonização das normas regulamentares e dos procedimentos administrativos.

Tal atribuição reparte-se entre o Conselho e o Grupo. Veja-se o art. 9 do Tratado de Assunção. "A administração e execução do presente Tratado e dos Acordos específicos e decisões que se adotem no quadro jurídico que o mesmo 
estabelece durante o período de transição estão a cargo dos seguintes órgãos:

- Conselho do Mercado Comum;

- Grupo Mercado Comum.”

O Protocolo de Ouro Preto, em seu art. $1^{\circ}$, acrescenta às duas primeiras, dois novos órgãos (III e V), e relaciona outros dois já existentes dando-lhes melhor posição hierárquica (IV e VI). O Mercosul passa a ser assim governado: "A estrutura institucional do Mercosul contará com os seguintes órgãos:

I - Conselho do Mercado Comum (CMC);

II - Grupo Mercado Comum (GMC);

III - Comissão de Comércio do Mercosul (CCM);

IV - Comissão Parlamentar Conjunta (CPC);

V - Foro Consultivo Econômico Social (FCES);

VI - Secretaria Administrativa do Mercosul (SAM).”

\section{O Conselho}

Com relação ao Mercado Comum, de que é o órgão superior a função do Conselho é "a condução política do mesmo e a tomada de decisões para assegurar o cumprimento dos objetivos e prazos estabelecidos para a constituição do mercado Comum.” (Tratado de Assunção, art. 10), ou (nos termos do art. 3( do Protocolo de Ouro Preto) a ele "incumbe a condução política do processo de integração e a tomada de decisões para assegurar o cumprimento dos objetivos estabelecidos pelo Tratado de Assunção e para lograr a constituição final do mercado comum"

Fica claro o caráter da atuação do Conselho, na sua função de condução política do processo de integração visando a alcançar o Mercado Comum. Se acrescentarmos a essa função a de tomada de decisões, como preconizada pelo art. 10 do Tratado de Assunção, veremos que o caráter político continua presente.

Finalmente, quanto ao seu modo de atuação, recordaremos que a regra é a da unanimidade (Tratado de Assunção art. 16; Protocolo de Ouro Preto, art. 37). Não há qualquer relação hierárquica entre o Conselho e os habitantes dos países do Mercosul.

\section{O Grupo}

O GMC é, segundo a letra do Tratado de Assunção (art. 13) e do Protocolo 
de Ouro Preto (art. 10), “o órgão executivo do Mercado Comum, e será coordenado pelos Ministros do Exterior".

Suas funções que no Tratado de Assunção (art. 13) incluíam "velar pelo cumprimento do Tratado; tomar as providências necessárias ao cumprimento das decisões adotadas pelo Conselho; propor medidas concretas tendentes à aplicação do Programa de Liberação Comercial, à coordenação de políticas macroeconômicas e à negociação de Acordos frente a terceiros; fixar programas de trabalho que assegurem avanços para o estabelecimento do Mercado Comum", passam a ser mais especificadas pelo art. 14 do Protocolo de Ouro Preto, sem que o conteúdo seja alterado substancialmente, apenas se acrescentando novas funções, em especial a de negociar tratados por delegação do CMC.

Entretanto, a leitura das funções atribuídas ao órgão mostra que o caráter executivo anunciado pelo art. 10 do Protocolo de Ouro Preto não é exclusivo. Com efeito, as funções atribuídas ao gmc incluem algumas de natureza opinativa ou homologatória (cf. art. 14, itens VI, VII, XIV), assim como outras de caráter fiscalizador (itens VII e XIII). Mas como poderia ser de outro modo, se apenas a SAM está submetida ao GMC?

As observações feitas a propósito do funcionamento do Conselho quanto ao modo de tomada de decisões e alcance das mesmas aplicam-se ao GMC, que de certa forma, desenvolve atividades de apoio ao referido Conselho.

\section{A Secretaria}

A antiga Secretaria do GMC, atual Secretaria Administrativa do Mercosul (SAM) é a que mais se aproximaria do germe de uma instituição supranacional, ocorrendo compará-la com a secretaria do GATT, pré-rodada Uruguai. Independentemente dessa comparação, logo vemos que a Secretaria tem por finalidade a guarda de documentos e a comunicação de atividades do GMC, assim como o desenvolvimento de atividades de apoio ao CMC, GMC, e CCM. Faltando-lhe qualquer poder de iniciativa e dada a limitação de suas funções e subordinação ao GMC, (v. Regimento Interno do GMC, art. 32 e 33) não haveria que cogitar em organização internacional. Esta, ainda teria de ser criada. Acresce que a Secretaria Administrativa apenas tem relações com o GMC e os subgrupos de trabalho.

Entretanto, o caráter diplomático atual dessas instituições do Mercosul, que parecia ser questionado quanto ao seu futuro pela expressão "Durante o período de transição", inserida no início do art. 16 do Tratado de Assunção, foi confirmado categoricamente pelo Protocolo de Ouro Preto. Este criou novos órgãos, como a Comissão de Comércio do Mercosul e o Foro Consultivo Econômico Social, mas estes, bem examinados, são complementares do CMCe do GMC. 
Mas, se atentarmos para a história do processo de integração que levou ao Mercosul veremos que as condições políticas que levaram à escolha de instituições de caráter diplomático aparentemente não mudaram. O avanço do processo de integração continuará e a pressão de certos setores da doutrina faz-se no sentido de mudança para um sistema em que a normatividade seja supranacional. Seria o caso de mudar o caráter dessas instituições?

Iremos enfrentar esta questão após o exame do mecanismo de solução de disputas.

\section{Subsistema de solução de disputa}

Em nenhum dos aspectos das instituições do Mercosul o caráter político e o diplomático ficaram tão evidentes como no sistema de solução de disputas. Desde o seu esboço, no Tratado de Assunção, até os detalhes do Protocolo de Brasília e a inserção da CCM pelo Protocolo de Ouro Preto, vemos o predomínio da atividade diplomática sobre qualquer outra; apenas um aceno é feito, no art. 44 do Protocolo de Ouro Preto.

O Protocolo de Brasília, dando seqüência ao desenho feito pelo Tratado de Assunção, prevê que a solução de disputas ocorrerá no plano diplomático, através de negociações diretas, da intervenção do GMC e, por último, do procedimento arbitral.

Tanto as negociações diretas como a intervenção do GMC são procedimentos tipicamente de cooperação, diplomáticos. A intervenção do GMC consiste na formulação de recomendações, tal como ocorre nos painéis do GATT. Não se trata nem da noção tradicional de bons ofícios, nem da conciliação ou mediação, mas, sem sombra de dúvida, procedimento diplomático. Somente falhando tal procedimento, recorre-se à arbitragem.

Num sistema como o europeu, a solução foi forçosamente outra. Lá, a instituição União Européia tem jurisdição própria e a Corte, também, no âmbito próprio de suas funções judicantes.

A supranacionalidade da União Européia e de seus órgãos permite-nos falar em competências e jurisdição, o que não ocorre em uma instituição de cooperação, como o Mercosul.

Outra importante conseqüência da escolha institucional do Mercosul refere-se ao acesso dos cidadãos aos mecanismos de solução de disputas. Os cidadãos, como se sabe, têm acesso direto à Corte Européia.

No caso do Mercosul, não havendo contato direto entre a população e suas instituições, teoricamente não se justifica o acesso direto daquela ao meca- 
nismo de solução de disputas. Entretanto, por engenhoso mecanismo, os cidadãos do MERCOSUL têm acesso, por via indireta, ao mecanismo de solução de divergências. Este se faz por intermédio dos governos, no interior de cada Estado, dentro do quadro tradicional da proteção diplomática, a qual deixa de ser ato discricionário, passando a ter caráter legal quando determinadas condições se reunirem. Trata-se, ao mesmo tempo, de progresso e da reafirmação do caráter de cooperação do sistema, encerrando a negativa de supranacionalidade às instituições permanentes.

Por último, o caráter ad hoc do mecanismo arbitral completa o quadro.

\section{Mecanismos de integração de natureza econômico-fiscal}

Além das instituições de caráter político, com funções normativas e de controle interno, inclusive para solução de controvérsias, o Mercosul tem instituições de natureza econômica.

O processo de redução linear, gradual e automática das tarifas, a tarifa única comum e as políticas macroeconômicas coordenadas, os princípios da gradualidade e da reciprocidade, estão entre as instituições mais importantes. Elas podem ser divididas em duas categorias: as transitórias e as permanentes.

\section{Instituições econômicas transitórias}

As instituições econômicas transitórias miram o estabelecimento de uma zona aduaneira comum e sua função se esgota quando esta é alcançada. A primeira e mais importante delas visa às tarifas alfandegárias; as duas outras, à natureza do processo de integração de modo geral.

\section{Redução linear, gradual e automática das tarifas}

Este é outro aspecto inovador e importante na estrutura do Tratado de Assunção, no qual o modo de se chegar à eliminação das tarifas nas operações internas do Mercosul é o estabelecimento de uma progressão negativa das mesmas.

O processo de redução linear, gradual e automática das tarifas constituiu o que se denominou um tratamento de choque aduaneiro (8). Ele rompe a tradição dos programas de integração da América Latina (9) e tem como objetivo último alcançar uma tarifa única comum. Políticas macroeconômicas coordenadas sucede-la-ão e completá-la-ão.

O programa de liberação comercial, previsto nos anexos do tratado de Assunção, "que consistirá em reduções tarifárias progressivas, lineares e automáticas, acompanhadas da eliminação de restrições não-tarifária ou medidas de efeito 
equivalente" (10) é, exatamente, o mecanismo-quadro necessário para - eliminando tarifas - chegar à zona de livre comércio.

\section{As listas de exceções}

Seguiu-se aí, novamente, o modelo estabelecido no Acordo de Complementação Econômica $\mathrm{n}^{\circ} 14$. Os produtos considerados mais delicados ou sensíveis ficaram protegidos por mais tempo, amparados que foram por listas de exceções, que serão reduzidas anualmente em $20 \%$, para que não mais subsistissem a partir do primeiro dia de 1995.

Essas listas atendem à diversidade dos Estados-partes e visam também a proteger os dois parceiros economicamente menores, Paraguai e Uruguai. Assim, ambos os países já teriam instaurado, em 1995, o Mercado Comum, com respectivamente 88 e 192 itens protegidos. Agora, com as modificações recéminstituídas, o número de produtos que integram as listas de exceção é de 300 por país, acrescida no caso do Paraguai de 99 itens adicionais, além de o prazo ter sido estendido para o ano 2000.

A adoção de tal fórmula permitiu que chegássemos, no curto prazo de quatro anos, a uma Tarifa Externa Comum (embora com exceções) e, conseqüentemente, à zona de livre comércio. Com a eliminação das exceções, teremos a zona aduaneira comum plenamente instaurada.

O simples fato de que ao alcançar seus objetivos o procedimento de redução constante e linear de alíquotas se esgota, coloca-o no rol das instituições transitórias destinadas a desaparecimento quando forem alcançadas as metas de integração do Tratado de Assunção.

As listas de exceções são a válvula de segurança contra as pressões decorrentes da aplicação do processo de redução de tarifas, protegendo alguns setores industriais ou atividades econômicas que seriam ameaçados pela eliminação das tarifas. Mas mesmo esta exceção é temporária e transitória. Insere-se no que se convencionou chamar de gradualismo da integração. Este corresponde à aplicação do chamado princípio da gradualidade que, segundo José Ângelo Estrella Faria, "traduz o desejo dos governos envolvidos de promover a integração paulatinamente, com o intuito de 'dar tempo ao tempo para que setores produtivos nos dois países se ajustassem às contingências criadas pela abertura parcial e seletiva dos mercados'...” (11).

A aplicação desse principio resultou na criação de uma série de etapas, reajustáveis, nas quais determinados objetivos devem ser alcançados como condicionante da etapa posterior.

Sem sombra de dúvida, o princípio da gradualidade associa-se com a flexi- 
bilidade a que se refere o Preâmbulo do Tratado de Assunção. Pela sua localização ela é, como bem apontou Estrella Faria, "uma diretiva de procedimento para a tomada das deliberações necessárias" além de "constituir um dos elementos primários para sua interpretação...” (12).

\section{Instituições econômicas permanentes}

\section{Reciprocidade}

$\mathrm{O}$ art. $2^{\circ}$ do Tratado de Assunção contém outra regra básica do Mercosul: a reciprocidade. Com efeito, ali pode-se ler: "O Mercado Comum será fundado na reciprocidade de direitos e obrigações entre os Estados-partes".

O princípio da reciprocidade sempre foi parte do direito internacional brasileiro, mas por certo tempo sua importância foi ofuscada pela ferrenha oposição que lhe fazia Haroldo Valadão, fundado em seu apego a uma posição ideológica, que impedia o ilustre professor de ver a importância prática da mesma.

Celso Lafer, numa obra importante e precursora (13), restaurou a validade teórica desse princípio em nosso direito internacional. Uma referência feita a Levi Strauss no seu texto, encaixa-se muito bem no quadro da integração no cone sul. Aí, Celso Lafer lembra que, para o antropólogo, a reciprocidade é "um processo pelo qual se passa da hostilidade à aliança, da ansiedade à confiança, do medo à amizade". Além disso, ensina-nos também que "a reciprocidade pode ser vista como uma 'fórmula de procura' no processo de consolidação da interação social, econômica e política" (14). E o que são as instituições do Mercosul senão uma "fórmula de procura mais ampla, no campo da integração?

A reciprocidade referida no Tratado de Assunção corresponde àquela a que se refere a definição clássica (15). Mas a reciprocidade no campo econômico tem sua maneira de ser especial, que reside na avaliação subjetiva e objetiva das prestações, afetada, sempre, pela influência do tempo no conteúdo das obrigações.

Sem sombra de dúvida - pelo fato de o Mercosul ser um mecanismo de cooperação, dos que se estendem ao longo do tempo, alargando-se, no quadro institucional que estamos examinando -, a avaliação das prestações recíprocas será cada vez mais difícil, embora a reciprocidade seja elemento indispensável das suas instituições. Como lembra José Ângelo Estrella Faria, (16) "a regra da reciprocidade não se destina a regular os efeitos do Tratado na ordem interna dos Estados-partes, mas sim, como ali está dito, a reger as relações entre as partes no âmbito do próprio Tratado".

Trata-se aí da reciprocidade formal, de direitos e obrigações, tal como a prevista no GATT (17), e tem como finalidade levar ao aperfeiçoamento, por via 
da complementação do Tratado, e à consecução de seus objetivos. Para isso, insere-se como mecanismo de controle da execução do Tratado de Assunção.

Mas essa inserção se faz de modo cooperativo e, por isso, a reciprocidade sempre em decorrência do Tratado de Assunção - deve ser aplicada na ordem interna, enquanto nesta se implementam, efetivamente, os mecanismos integracionistas (18).

Por aí se vê que as instituições de integração de caráter cooperativo possuem seus mecanismos próprios, os quais fazem com que as condutas dos Estados se adaptem ao objetivo comum, esposado com os parceiros, de criação do Mercosul.

\section{Tarifa externa comum e reciprocidade}

Outra instituição do Mercosul é a Tarifa Externa Comum (TEC). Seu papel é o de cimento da unidade do mercado, está associada intimamente à livre circulação de mercadorias e à harmonização de políticas e do direito dos Estadosmembros.

A TEC associa-se à ausência de tarifas no interior da zona integrada, que decorre do art. $1^{\circ}$ alínea primeira, combinados com o art. $2^{\circ}$ do anexo I do Tratado de Assunção, no qual se prevê a eliminação dos "direitos aduaneiros e quaisquer outras medidas de efeito equivalente... que incidam sobre o comércio exterior" do Mercosul.

Eliminada a tarifa no interior do Mercado seria imprescindível, para seu funcionamento, que houvesse uma TEC, respeitando-se a lógica do sistema implantado.

Teoricamente, pode ocorrer - e ocorre hoje no caso do Mercosul - que haja exceções - temporárias - à TEC. Mas estas são limitadas em número, objeto e tempo, e decorrem do gradualismo das instituições criadas pelo Tratado de Assunção.

Além das tarifas há obstáculos, de várias naturezas, que se convencionou colocar na mesma e ampla categoria das barreiras não-tarifárias. Estas devem ser eliminadas e, em tal aspecto, o mecanismo de cooperação se faz de novo presente.

A eliminação das barreiras não-tarifária é concretizada por medidas tomadas no interior de cada país, por iniciativa própria ou resultante de deliberação no seio do GCM, ou de um dos subgrupos especializados.

\section{Harmonização}

O instituto da harmonização é outra das características do Mercosul. Não 
falarei da harmonização de políticas macroeconômicas, apesar da sua importância e de quanto a seu respeito se escreveu, mas focalizarei a do direito dos países do Mercosul. Ela é uma obrigação dos Estados-partes, que devem "harmonizar suas legislações, nas áreas pertinentes, para lograr o processo de integração"(art. $1^{\circ}$ in fine).

Podemos, assim, darmo-nos por convencidos de que, na união aduaneira ou no mercado comum, há a meta de harmonização de legislações "nas áreas pertinentes, para lograr o processo de integração".

Que visariam os autores do Tratado de Assunção ao estabelecer como meta a harmonização do direito? Qual a importância que esse procedimento teria na formação do mercado comum?

Segundo Clóvis Beviláqua (19), Aristóteles teria dito que “o direito não é como o fogo, que arde do mesmo modo na Pérsia e na Grécia”, apontando para a diversidade de sistemas jurídicos existente desde então. Recordando a narrativa bíblica da torre de Babel, pode-se pensar que aí teria tido início a separação entre os direitos pela associação inevitável entre estes e a linguagem. Entretanto, o que importa é registrar a antigüidade da separação dos sistemas jurídicos, decorrente de histórias e ambientes diversos dos povos que os empregam, ou seja, de circunstâncias diferentes.

O comércio internacional leva, naturalmente, à aproximação, sobretudo econômica, dos países. Reclama segurança jurídica. A função de coordenação, assumida pelo direito internacional privado clássico, através do mecanismo de conflito de leis é o instrumento clássico para assegurar essa segurança. Entretanto, além de suas deficiências - decorrentes da própria história e da mutação dos conceitos - é francamente insuficiente ou inadequada quando ocorrem grandes volumes de comércio.

O exemplo clássico é o dos Estados Unidos da América, onde conviviam e convivem diversas normas estaduais, cuja coordenação se faz num complexo sistema de conflito de leis. Lá, a necessidade de maior segurança jurídica e agilidade em temas como o comércio ou os pagamentos têm levado à adoção de leis uniformes, como o UCC (20), entre outras.

Assim, também no âmbito do espaço econômico do Mercosul, teremos que superar a fase da coordenação pelo conflito de leis, para entrar na da harmonização do direito.

Tradicionalmente, os internacional-privatistas e os comparatistas têm enveredado pelo caminho da uniformização do direito (21) recorrendo ao que se chamou de direito uniforme dirigido, ou direito uniformizado; quer dizer, a adoção de regras uniformes - sejam elas tratados e convenções, portando leis 
uniformes, costumes codificados ou regulamentos de livre adoção pelas partes (como os propostos pela $\mathrm{CCI}$ e, mais modernamente, por alguns organismos da ONU).

Não se pode deixar de creditar ao gênio de Pascoale Mancini a iniciativa, nos tempos modernos, de propor a uniformização do direito pela via dos tratados internacionais, tendo sido seguido por Ernst Zittelmann, o teórico do weltsrecht. No Brasil, o primeiro a advogar o direito uniformizado foi João Monteiro, professor das Arcadas (22). Até então, não se distinguia entre unificação e harmonização. Hoje, além dessas categorias, há quem distinga, também, na primeira, o direito uniforme espontâneo e o uniformizado.

O primeiro seria aquele que decorre de uma genealogia jurídica comum, como ocorre nos países de independências mais recentes, onde o direito do colonizador se aplica. Exemplificam tal tendência a Austrália, o Canadá, a Nigéria, entre outros que adotaram o sistema inglês, ou da common law. Outras vezes, como no caso do Japão, do Líbano ou da Turquia, decorre da adoção de códigos de outros países ou feitos sob encomenda por jurisconsultos estrangeiros para substituir, naquele Estado, um direito costumeiro ou de regiões, grupos religiosos etc.

Esse tipo de uniformização, como bem aponta Jacob Dolinger (23), endereça-se sobretudo ao direito interno. $\mathrm{O}$ grande interesse na uniformização, entretanto, dirige-se para as instituições jurídicas que "atuam total ou parcialmente no plano internacional, como os títulos de crédito, os transportes, as comunicações, a propriedade industrial e intelectual, a compra e venda, e todas as atividades humanas naturalmente extraterritoriais" (24).

Josephus (25) sustentava que o Direito Internacional Privado seria o instrumento de harmonização e que a uniformidade, decorrente do direito uniforme, a complementaria. Ao nosso ver, o direito internacional privado tem aspectos de harmonização, mas é sobretudo um direito de coordenação. Ademais, já existe nos países do Mercosul. Não é esse, pois, o visado pelo Tratado de Assunção no art. citado.

Com efeito, a noção de harmonia repousa no conciliar, no congraçar, na disposição bem ordenada das partes de um todo, no acordo, na conformidade. São harmônicos, sem sombra de dúvida, os sistemas jurídicos que tenham semelhanças espontâneas, ou induzidas, nos seus aspectos materiais e essenciais, que apresentem paralelismos, ainda que sejam dissemelhantes em outros aspectos. São-no também os que se apresentem bem ordenados como partes de um todo, que estejam em conformidade com relação aos seus princípios e efeitos.

Na harmonização o que temos são direitos cujos princípios são harmônicos, 
isto é, concordes, embora suas regras possam não ter igual teor. Dessa forma, poderíamos dizer que os direitos dos países do Mercosul são, de modo geral, harmônicos, já que divergem apenas em aspectos particulares, embora as normas sejam formalmente desiguais.

Com efeito, as normas de direito privado relativas aos contratos, por exemplo, são, sem sombra de dúvida, harmônicas e dificilmente teríamos aspectos em que divergissem de modo significativo, já que descendem da mesma cepa genética: o direito romano. Ademais, a fase histórica em que estiveram submetidos aos mesmos soberanos representou nova oportunidade de ajustes harmonizadores, apesar de o rei da Espanha ter conservado Portugal como reino unido.

Mas, em razão de descompassos no processo histórico-econômico da vida de cada um desses países, temos aspectos em que as suas respectivas legislações não são harmônicas: é o caso, por exemplo, da proteção ao consumidor, em que o Brasil se adiantou aos demais países, seguido recentemente pela Argentina, estando ainda Paraguai e Uruguai na visão clássica, pré-sociedade de massas, da responsabilidade aquiliana ou contratual pelo fato do produto (26). No que se refere à empresa, ao direito do trabalho, às sociedades, ao processo falimentar, à concorrência, à metrologia, aos tributos, certamente há de se harmonizar os direitos dos países do Mercosul. O elenco é longo.

A harmonização, finalmente, se insere no quadro institucional da cooperação, pois, se o Mercosul tivesse sido organizado sob a égide de instituições supranacionais, estas teriam certamente competência legislativa e estariam unificando - e não harmonizando - o direito. Mais ainda, estariam substituindo o direito vigente por outro, novo e único, como ocorreu em certos casos na CEE e ocorre na sua sucessora, a União Européia.

A elaboração das instituições, que passaremos a examinar, foi feita segundo a perspectiva da cooperação.

\section{Prospectiva da elaboração das instituições e de aspectos normativos do Mercosul}

Ao visualizar a elaboração das instituições do Mercosul - e suas perspectivas - será preciso partir de duplo enfoque: político e econômico, para depois discutir as alternativas que nos convém. O primeiro prender-se-á ao que vejo como um projeto nacional. Trata-se, evidentemente, de expor aqui um modo de ver pessoal e subjetivo. Realmente, por se tratar de políticas in fieri, entendi que seria importante acrescentar mais um ponto de vista aos que certamente já existem a propósito do desenho futuro do Mercosul. O segundo refere-se aos órgãos do Mercosul. 


\section{Aspectos políticos e econômicos}

O Mercosul, embora resultante desses fatores, apresenta-se como uma situação diferente daquela existente à época dos acordos Brasil Argentina, celebrados no fim dos anos oitenta.

Os acordos visavam a um processo de integração global, em que uma proposta de desenvolvimento tecnológico se sobrepunha e complementava o projeto de integração comercial.

O Tratado de Assunção, por sua parte, enfatiza apenas este último aspecto, por razões que o tempo e a natureza dos parceiros explicam, e que não serão aqui duscutidas.

Acrescente-se à origem a diferença de ritmo preconizada e seguida, de um lado por Brasil e Argentina e, de outro, por Uruguai e Paraguai face aos parceiros no Mercosul. Essa foi ressaltada na última rodada de negociações, quando da VI Reunião do Conselho do Mercosul.

Examinando-se as políticas de desenvolvimento dos quatro países, nas quais as divergências decorrem das características geográficas, demográficas e econômicas, vê-se claramente porque não se pode e não se deve aceitar uma estrutura demasiadamente rígida para o Mercosul. Esta impedirá ao Brasil não só de prosseguir suas políticas nacionais, como sua tentativa de afirmar-se como país capaz de desenvolver-se tecnologicamente e alcançar condições que lhe permitam atingir a importância internacional que suas dimensões justificam.

Para atingir a competência tecnológica impõe-se o recurso à cooperação industrial como ferramenta estratégica da política que o Brasil pretende seguir. Era o que Brasil e Argentina visavam a alcançar, nos anos 80, por meio dos seus acordos nas áreas nuclear, financeira, industrial, de aeronáutica, de biotecnologia.

A visão e o projeto argentinos mudaram desde então, como ocorreu no Brasil, mas essa mudança não foi paralela, nem no mesmo grau nos dois países, cabendo perguntar, ainda, se os dois outros parceiros, Paraguai e Uruguai, têm alguma contribuição a dar nesse plano. Se o papel destes últimos limitar-se-á, como parece, aos aspectos comercial e político da integração, então não convém criar instituições que nos amarrem mais do que as atuais, as quais, para as finalidades até de se chegar a um mercado comum, são suficientes.

Por outro lado, temos uma realidade de grandes diversidades geográficas e demográficas no Mercosul. Essas, sem sombra de dúvida, impõem políticas decorrentes das peculiaridades de cada país, como se disse a propósito do desenvolvimento tecnológico e da política industrial. 
Instituições administrativas que pudessem influir sobre essas políticas teriam que, ou ser incapazes de afetar a possibilidade de cada qual desenvolver essas políticas, ou decorrer do interesse da maioria. Para tanto, seria necessária uma ponderação no voto, como se utiliza na Europa, mas em que os índices de ponderação, se proporcionais à população territórios e recursos, resultariam num tal predomínio brasileiro que seriam inaceitáveis para os demais parceiros. E, pela mesma razão, índices que não respeitassem essas proporções seriam inaceitáveis para nós. Está visto que o modelo de supranacionalidade europeu, viabilizado pela ponderação dos votos, apresentar-nos-ia dificuldades enormes, se não insuperáveis.

Numa estrutura como a européia, em que a Comissão tem poder não só de iniciativa, mas em certos casos normativo, supranacional (e este se expande com a cooperação ativa do Tribunal), por essa forma também aumenta o seu próprio poder (27). Nessa estrutura, caso a ponderação do voto não fosse adequada, os interesses brasileiros poderiam vir a ser prejudicados de forma permanente e irremediável, com o futuro do país sacrificado.

A este passo, deve-se ponderar que o Mercosul, na prática, nunca poderá representar mais que um percentual - e relativamente pequeno - do total das exportações brasileiras. E estas, ao que sugere o panorama deste fim de século, deverão depender também da celebração de acordos bilaterais e do acesso a outros mercados.

Portanto, a primeira conclusão a que chego é a de que, em nossos dias, do ponto de vista político e econômico, órgãos de administração com poder semelhante ao daqueles da União Européia são inadequados e essa parece ter sido a preocupação do governo tanto na elaboração do Tratado de Assunção como no Protocolo de Ouro Preto.

Por outro lado, parece-me impossível evitar certo grau de atividade administrativa comunitária, assim como o mecanismo de solução de disputas poderia ainda ser aperfeiçoado, sem modificações substanciais. Partindo do exposto, creio que poderíamos fixar alguns parâmetros para os órgãos administrativos do Mercosul.

\section{Parâmetros institucionais}

Trata-se aqui, fundamentalmente, de matéria de limites para a ação institucional. $\mathrm{O}$ que as ordens constitucionais impõem e, também, aqueles limites de natureza política que a vontade nacional traça, aos quais já fizemos referência.

Vejamos os obstáculos na ordem constitucional para a criação de organismos supranacionais nos moldes daqueles utilizados na União Européia, tanto 
para o exercício de funções normativas quanto das judiciais e, em parte, pelo menos, das administrativas.

A principal função dos órgãos supranacionais da União Européia, que é a de expedir normativas e regulamentos comunitários encontra, com certeza, forte obstáculo na ordem constitucional brasileira.

Um organismo como o Conselho da União Européia acumula funções de iniciativa legislativas com as administrativas, o que, parece-me, afronta a regra da separação dos poderes que faz parte da chamada cláusula pétrea da Constituição.

Os artigos 22 a 24 da Constituição Federal estabelecem competências legislativas, tanto as privativas da União quanto as concorrentes, desta e dos estados ou municípios. A competência para legislar sobre comércio exterior, transportes, direito civil, comercial etc. é privativa da União. Privativa e indelegável pelo legislativo ao executivo. Na Europa, onde os regimes são todos parlamentaristas, executivo e parlamento se confundem e o primeiro é delegado do segundo. Aqui, a delegação ao executivo é direta, do eleitorado ao mandatário; lá, indireta - legisladores escolhem o executivo, e escolhem-no em razão de maiorias parlamentares. É esse um importante obstáculo à criação de órgãos comunitários com o poder de editar normas, como ocorreu na União Européia; sem reforma estrutural da forma de governo parece-me inviável a ratificação de tratados conferindo poder normativo supranacional aos órgãos comunitários. Acresce a esses obstáculos o fato de que o relacionamento básico e fundamental do Mercosul é aquele do eixo Brasil e Argentina. Na União Européia, começou-se com cinco países, cujos pesos relativos eram próximos, enquanto o Mercosul se compõe de dois grandes e dois pequenos países.

A competência legislativa própria dos órgãos comunitários, portanto, mercê dos limites constitucionais, seria inexistente, o que nos forçaria a continuar com o processo atual de criar normas pela via dos tratados (tal como ocorreu, aliás com sucesso, no âmbito do Benelux). Logo, o sistema deve continuar a ser o da cooperação, e não o da supranacionalidade, pelos menos, nos próximos lustros.

\section{A função de solução de disputas: perspectivas}

Diz-se que na história da integração da Europa, desde a Ceca até nossos dias, houve um governo de juizes e mesmo importantes estudos foram feitos para mostrar o papel decisivo da Corte naquele processo de integração (28).

A criação de um Tribunal do Mercosul, nos moldes da Corte Européia ou do Tribunal Andino, encontra forte obstáculo constitucional. Realmente, o art. 92 da Constituição Federal estabelece, sob forma de relação, quais são os órgãos do Poder Judiciário, o que aparentemente é forma de dizer que estamos diante de numerus clausus. 
Por outro lado, uma das garantias individuais mais tradicionais em nossas constituições, da qual trata o art. $5^{\circ}$ Xxxv da atual, é que: "A lei não excluirá da apreciação do Poder Judiciário lesão ou ameaça a direito", de onde se poderia deduzir que, para pessoas residentes no Brasil, vindo a lei a qualquer questão, mesmo em matéria comunitária, deverá, sempre, passar pelo crivo dos Tribunais, e que não se pode criar outros além dos mencionados na Constituição. Esta, na seqüência de tal raciocínio, deveria ser reformulada visando a permitir a inclusão, no rol constitucional brasileiro, de um tribunal comunitário, para que uma Corte de Justiça do Mercosul pudesse ser criada (29) e suas decisões serem eficazes.

Se esse Tribunal existisse, como na Corte Européia, sua competência deveria abranger as relações dos particulares com a entidade comunitária, as normas transnacionais comunitárias, e as divergências entre os Estados.

Restava a solução da arbitragem, já implantada em caráter internacional e obrigatória pelo Protocolo de Brasília e que visa às divergências entre Estados (inclusive aquelas oriundas do setor privado e incorporadas pela via da proteção diplomática).

Criticam-na por seu caráter ad-hoc, que não permitiria a formação de jurisprudência e tornaria o processo mais um problema jurídico a ser resolvido em cada caso.

A resposta a essas críticas é a transformação da corte arbitral, de $a d$-hoc em permanente, atribuindo-se-lhe um regimento interno que regularia o processo, e daria certa estabilidade à função dos árbitros (por exemplo, estabelecendo-lhes mandato). O modelo, testado, já está pronto, tanto na Corte Permanente Arbitral da Haia, quanto na do Benelux.

Teríamos, com isso o perigo de um governo de árbitros no Mercosul, nos moldes do chamado governo dos juizes da União Européia?

Não nos parece o caso, pois, ao contrário do mecanismo europeu, apenas as altas partes contratantes têm o poder de acionar o mecanismo arbitral e o fazem somente tendo esgotado todos os demais procedimentos previstos no Protocolo de Brasília. A isso se deve acrescentar que os árbitros só poderão agir nos limites da lide, fixados pelas partes caso a caso, o que lhes tira todo o poder de suprir as carências da instituição ou modificar a visão que dela têm, coletivamente, os Estados do Mercosul.

Recorde-se que na União Econômica Belgo-Luxemburguesa, em trinta anos de funcionamento, a instituição arbitral não teve um só caso. No Benelux encontrei registro de apenas um caso nos dez primeiros anos de funcionamento. $\mathrm{Na}$ vigência do Protocolo de Brasília não houve sequer um caso de arbitragem. 
Isso mostra que não há quase campo para disputas jurídicas em projetos de integração de caráter cooperativo, como o do Mercosul, tal como se desenvolveu até hoje. O conteúdo das divergências, quando as houve, foi predominantemente político e, por isso, resolvido por via diplomática.

Outro aperfeiçoamento possível seria aumentar a competência do tribunal arbitral para proferir decisões declaratórias, interpretando o Tratado de Assunção ou dos documentos dele decorrentes - com caráter vinculante para os Estados Membros, - que, dessa forma, teriam uma interpretação uniforme.

\section{Conclusão}

O diferenciador do Mercosul é estar baseado em estreita cooperação intergovernamental. Difere nesse ponto da experiência das Comunidades Européias, que desde a sua origem confiaram problemas políticos importantes a instituições independentes dos governos.

Notas

l J.F. Rezek, Direito dos Tratados, Rio de Janeiro, 1984, p. 447.

2 Idem, p 454.

3 A expressão parece ter sido empregada pela primeira vez no Tratado de Roma que criou a CEE. O GATT ao referir-se a mecanismos de integração econômica, no seu art. xxIv, fala tão só de zona de livre comércio e união aduaneira, o que em parte se explica pela ótica desta convenção, a qual focaliza apenas os aspectos comerciais das relações entre os Estados.

4 Cf. Tratado de Assunção, art. 11, e Protocolo de Ouro Preto, art. 4.

5 "[q]ue representem os seguintes órgãos públicos: Ministério das Relações Exteriores; Ministério da Economia ou seus equivalentes (áreas de indústria, comercio exterior e ou coordenação econômica); Banco Central" podendo, inclusive "convocar, quando julgar conveniente, representantes de outros órgãos da Administração Pública" (Tratado de Assunção, art. 14), ou em outras palavras "quatro membros titulares e quatro membros alternos por país, designados pelos respectivos governos, dentre os quais devem constar necessariamente representantes dos Ministérios das Relações Exteriores, da Economia (ou equivalentes) e dos Bancos Centrais"(Protocolo de Ouro Preto, art. 11)

6 A expressão é usada no sentido de exercício de poder e não na de fiscalização, tal como se usa no direito societário, poder de controle.

7 O Protocolo de Ouro Preto, concedendo personalidade jurídica ao Mercosul, criou a representação do mesmo pelo CMC (art. 8, III). 
8 Felix Peña. El Mercosur y sus perspectivas: una opción por la inserción competitiva mundial, conferencia proferida no Seminario sobre Las perspectivas de los Procesos de Integración Subregional en América Latina y América del Sur, Bruxelas, 4-5 de novembro de 1991 [mimeo. s.e.].

9 Embora seja a repetição do que se convencionou no Acordo de Complementação Econômica 14, entre Brasil e Argentina.

10 Coletânea de informações sobre o Mercosul, Decla/Mre, p.4.

110 Mercosul: princípios, finalidade e alcance do Tratado de Assunção, Coleção Integração Regional, Brasília, IPRI P. 4.

12 Idem, p. 6.

13 Da reciprocidade no direito econômico internacional econômico - o convênio do café de 1976. Tese, concurso para Livre Docente de Direito Internacional Público do Departamento de Direito Internacional da Faculdade de Direito da Universidade de S. Paulo. O pensamento de Celso Lafer informou a reflexão desta seção.

14 Idem, p. 40.

15 "Situation que se présente quand un État assure ou promet à un autre État, à ses agents, à ses nationaux, à son commerce, etc., un traitement égal ou équivalent à celui que ce dernier État lui assure ou lui promet”. Union Académique International. Dictionnaire de la Terminologie du Droit International, Paris: Sirey, 1960, p. 504505 .

16 Mercosul: Princípios..., cit. p. 16.

17 Art. II, parágrafo 1, "a", - "treatment no less favorable than the provided for in the appropriate Part of the appropriate Schedule annexed to this Agreement".

18 Cf. a propósito Michel Virally, La Réciprocité en Droit International, RCADI, 1967/ III, p 28.

19 Principios Elementares de Direito Internacional Privado, $3^{\text {a }}$. ed. Rio de Janeiro, Freitas Bastos, 1938. p 15, nota 1.

20 Uniform Commercial Code, uma codificação das normas comerciais dos EUA, feita em nível federal e que obriga os Estados.

21 Cf. Jacob Dolinger, Direito Internacional Privado, $2^{2}$. ed. atualizada, Rio de Janeiro, Renovar, 1993, p.32 e ss.

22 João Monteiro, "Uniformização do Direito - Cosmópolis do Direito - Unidade do Direito" o Mestre propugnava "uma língua para todos os povos, um direito para todas as sociedades. Eis o ideal: a humanidade confederada na harmonia inteligente da permuta universal de todas as manifestações da vida humana".

23 Direito Internacional Privado, cit. p 34-35.

24 Id. ibid. 
25 Método de Derecho Internacional Privado, p. 248 e ss.

26 Ver, do autor, Proteção do consumidor - aspectos de Direito Comparado e Internacional, São Paulo, Revista de Direito Mercantil, Industrial, Econômico e Financeiro, v. 83, jul./set. 1991, p. 18-32.

27 Cf. Hjalte Rasmussen, On law and policy in the European Court of Justice. Dordrecht, Martinus Nijhoff Publishers, 1986.

28 Id., ibid.

29 V. a propósito, do autor deste, A solução de disputas no Mercosul, artigo em vias de publicação na Revista de Informação Legislativa, no qual a matéria é abordada em mais detalhes.

Luiz Olavo Baptista é professor de Direito do Comércio Internacional da Faculdade de Direito da USP e doutor pela Universidade de Paris.

Palestra feita pelo autor no Conselho Superior de Orientação Jurídica da Federação da Indústria e Comércio (FIESP) em 21 de fevereiro de 1995. 